\title{
ПРОБЛЕМЫ И ПЕРСПЕКТИВЫ ПРАВОВОГО РЕГУЛИРОВАНИЯ ИСПОЛЬЗОВАНИЯ БОЛЬШИХ ДАННЫХ В РОССИЙСКОЙ ФЕДЕРАЦИИ
}

\author{
(c) 2021 Губайдуллина Эльмира Хамитовна \\ кандидат юридических наук \\ Самарский государственный экономический университет, Россия, Самара \\ E-mail: elmira_zaripova@mail.ru
}

\begin{abstract}
В статье исследуются проблемы правового регулирования применения Больших данных в различных сферах общественных отношений. Особое внимание уделено законодательным пробелам в защите Больших данных. Проведен сравнительный анализ понятий Большие данные и персональные данные. Выявлено, что основной проблемой правового регулирования Больших данных является необходимость защиты персональных данных физических лиц, поскольку значительная часть больших данных, так или иначе, касается сбора информации о конкретных субъектах.
\end{abstract}

Ключевые слова: Большие данные, big data, персональные данные, идентификация, информация, обработка данных, обезличенный характер, короновирус (Covid-19).

В настоящее время Большие данные являются одним из значимых направлений в развитии информационных технологий. Их используют в здравоохранении, торговле, логистике, в финансово-кредитных учреждениях и органах государственной власти. Огромные массивы данных обрабатываются для того, чтобы получить конкретные и нужные результаты для их эффективного использования. В «Стратегии развития отрасли информационных технологий в Российской Федерации на 2014-2020 гг. и на перспективу до 2025 г.» Большие данные указаны первыми среди «важнейших прорывных для мировой индустрии направлений, в которых в перспективе 10-15 лет с высокой вероятностью может быть обеспечена глобальная технологическая конкурентоспособность России»... [5].

Наряду с открывающимися возможностями и перспективами при использовании Больших данных возникает ряд вопросов правового регулирования таких данных в России.

Основной проблемой правового регулирования Больших данных является необходимость защиты персональных данных физических лиц, поскольку значительная часть больших данных, так или иначе, касается сбора информации о конкретных субъектах.

В Российском законодательстве до настоящего времени отсутствует четкий, законодательно закрепленный термин Большие данные (Big Data), а также отсутствуют нормы, регламентирующие права и обязанности участников сбора, хранения и использования информации.
При работе с Большими данными невозможно установить существует ли обязанность уведомлять субъект информации обо всех целях, способах и типах информации, которая будет собираться и обрабатываться.

Условия обработки персональных данных содержаться в п.1 ч.1 ст. 6 Федерального закона от 27.07.2006 № 152-Ф3 «О персональных данных», согласно которой, обработка персональных данных осуществляется с согласия субъекта персональных данных на обработку его персональных данных [11]. В соответствии со статьей 8 вышеуказанного закона размещение персональных данных субъектом в открытом доступе не позволяет считать такие сведения общедоступными источниками (в том числе справочники).

Аналогичной позиции также придерживаются суды и Федеральная служба по надзору в сфере связи, информационных технологий и массовых коммуникаций. Наглядным примером спорного использования Больших данных в России является спор сети «ВКонтакте» против ООО «Дабл». При вынесении решения судом указано, что размещение пользователями персональных данных в социальных сетях и на других Интернетресурсах не делает их «общедоступными» (Определение Верховного Суда Российской Федерации от 29 января 2018 г. № 305-КГ17-21291) [4]. В связи с тем, что в российском законодательстве закреплено конкретное определение персональных данных, целесообразно выделить отличие Больших данных от персональных данных [2].

Одним из критериев такого отличия мог бы 
стать обезличенный характер используемых данных.

Для анализа Больших данных применяется особая технология, при которой сведения о физическом лице аккумулируются в единое цифровое досье из разных ресурсов. Такие досье используется многократно. При этом цифровое досье постоянно обновляется и предполагает возможность использования дополнительных идентификаторов в изначально обезличенном досье.

После внесения таких дополнительных сведений, идентифицированные данные не являются обезличенными, а досье физического лица относится к персональным данным [7].

Еще одним критерием, по которому можно было отличить Большие данные от персональных данных является наличие информированного согласия на обработку данных физическим лицом.

Предполагается, что субъект данных соглашается с условиями обработки его персональных данных с первым оператором, но на дальнейшие виды обработки его данных он не может дать согласие, ввиду отсутствия информации о дальнейшей обработке персональных данных.

Соответственно, при использовании технологии Больших данных цель обработки персональных данных невозможно определить заранее, а сведения о субъектах могут быть повторно использованы.

Таким образом, в связи с возможностью идентификации Больших данных посредством применения дополнительных идентификаторов и многократного использования данных физических лиц, Большие данные не могут рассматриваться в отрыве от персональных данных [8].

В российском законодательстве неоднократно делались попытки разграничить Большие данные и персональные данные.

В конце 2018 года в Российской Федерации вносился законопроект № 571124-7 «О внесении изменений в Федеральный закон «Об информации, информационных технологиях и о защите информации», в котором предлагалось регулирование больших массивов данных аналогично персональным данным [10].

В частности, предлагалось дополнить данный закон статьей 12.2 «Оператор больших пользовательских данных до начала обработки больших пользовательских данных для целей третьих лиц обязан получить информирован- ное согласие в электронной форме пользователя абонентского терминала». В свою очередь, с Большими данными данные требования фактически невозможно исполнить. Впоследствии законопроект был отклонен [9].

В дальнейшем правовые нормы в отношении Больших данных были закреплены в «Законе о цифровых правах». С 1 октября 2019 года в целях защиты сбора и обработки значительных массивов обезличенной информации (Big Data) введено в ГК РФ условие заключения договора об оказании услуг по предоставлению информации (статья 783.1 ГК РФ). Такие договора обеспечивают защиту от разглашения информации третьим лицам [12].

Суды при вынесении решений в спорах об исполнении договорных обязательств, теперь исследуют договора с учетом норм, закрепленных ст. 783.1 ГК РФ (Апелляционное определение Верховного суда Республики Карелия от 14.01.2020 по делу N 33-92/2020) [1].

14 февраля 2020 года Министерством цифрового развития, связи и массовых коммуникаций Российской Федерации на официальном электронном сайте «regulation.gov.ru» был опубликован законопроект о регулировании Больших данных, который представлял собой поправки в Закон «Об информации, информационных технологиях и защите информации» [10]. Данный законопроект подготовлен во исполнение поручения президента по итогам послания Федеральному собранию 15 января 2020 года [6].

Основная задача вносимых изменений - это обеспечение регулирования оборота Больших данных с сохранением прав и свобод человека при обработке его персональных данных. Указанными поправками были введены такие термины как «Большие данные», «оператор Больших данных» и «обработка Больших данных», а также оговорен принцип создания реестра операторов Больших данных. Осуществление контроля за обработкой таких данных возлагалось на Роскомнадзор.

Однако данный законопроект 5 марта 2020 года отклонён Правительством РФ. Причиной отклонения законопроекта стал тот факт, что изменения широко определяют понятие «Большие данные», вводят излишнее регулирование для операторов таких данных, а также содержат коррупционные риски.

Так, термин «Больших данных» в предлагаемых поправках является попыткой разграни- 
чения персональных данных и Больших данных с учётом возможного отнесения к конкретной личности.

В свою очередь, под такую трактовку можно подвести любые сгруппированные данные, которые не являются персональными. Такое определение нельзя считать верным, так как оно требует конкретизации и уточнения.

На необходимость принятия в ближайшее время нормативно-правового акта, регулирующего Большие данные указывает сложившаяся ситуация в России, связанная с пандемией коронавируса (Covid-19).

В Интернете появилось много сайтов со сведениями о заболевших, выздоровевших и погибших от нового вируса. Так, Яндекс представил «Карту распространения коронавируса в России (с разбивкой по областям Российской Федерации) и мире», которую получил информацию от Роспотребнадзора и Университета Джонса Хопкинса в США (JHU) [3]. Безусловно, Большие данные становятся самым действенным способом для отслеживания распространения вируса для победы над пандемией, однако вопросы о правовой защите лиц, сведения о которых раз- глашаются, и о том, какие операторы могут располагать реальной информацией, остаются открытыми.

В связи с этим, целесообразно в нормах права, направленных на регулирование применения Больших данных предусмотреть ситуации сбора, аккумулирования и разглашения информации третьим лицам при чрезвычайных обстоятельствах (например, пандемии), в частности, утвердить круг операторов, осуществляющих сбор данных.

Изложенные обстоятельства позволяют сделать вывод о том, что в настоящее время на законодательном уровне отсутствуют достаточные правовые нормы, необходимые для регулирования оборота Больших данных: нет разграничения между Большими данными и персональными данными, законодательством не закреплен термин «Большие данные», не определены права и обязанности участников обрабатываемой информации. Данные факты могут привести к тому, что операции с Большими данными могут быть признаны незаконными и нарушающими основные права человека.

\section{Библиографический список}

1. Апелляционное определение Верховного суда Республики Карелия от 14.01. 2020 № 33-92/2020. [Электронный ресурс]. URL: http://www.consultant.ru/cons/cgi/online.cgi?req=doc \&base=SOSZ \&n=248971\#01356451657351594 (дата обращения: 05.04.2021)

2. Данилов A.Big Data: обзор и перспективы правового регулирования [Электронный pecypc]. URL: https:// danilovpartners.com/ru/publikacii/big-data-obzor-i-perspektivy-pravovogo-regulirovanija/ (дата обращения: 05.04.2021).

3. Карта распространения коронавируса в России и мире. [Электронный ресурc]. URL: https://yandex.ru/webmaps/covid19?1l=41.775580\%2C54.894027\&z=3 (дата обращения: 05.04.2021).

4. Определение Верховного Суда РФ от 29.01.2018 № 305-КГ17-21291 поделу NA40-5250/2017. [Электронный ресурс]. URL: http://www.consultant.ru/cons/cgi/online.cgi?req=doc \&base=SOSZ\&n=248971 \#01356451657351594 (дата обращения: 05.04.2021).

5. Паспорт национального проекта «Национальная программа «Цифровая экономика Российской Федерации» (утв. президиумом Совета при Президенте РФ по стратегическому развитию и национальным проектам, протокол от 04.06.2019 N 7). [Электронный ресурс]. URL: http://www.consultant.ru/document/cons_doc_ LAW_328854/9e733b9ece0472e8f17a73cd753a75784f9e1fab/ (дата обращения: 05.04.2021).

6. Перечень поручений по реализации Послания Президента Федеральному Собранию. [Электронный реcypc]. URL: http://www.kremlin.ru/acts/assignments/orders/62673 (дата обращения: 05.04.2021).

7. Романова А.Ю. К вопросу о правовом режиме Больших данных // Конституционное и муниципальное право. 2019. № 8. С. 20-25.

8. Савельев А. И. Направления регулирования Больших данных и защита неприкосновенности частной жизни в новых экономических реалиях // Закон. 2018. № 5. [Электронный ресурc]. URL: http://www.consultant.ru/ cons/cgi/online.cgi?req=doc \&base=CJI\&n=115818\#04757186887411553 (дата обращения: 05.04.2021).

9. Савельев А.И. Гражданско-правовые аспекты регулирования оборота данных в условиях попыток формирования цифровой экономики // Вестник гражданского права. 2020. № 1. [Электронный ресуpc]. URL: http:// www.consultant.ru/cons/cgi/online.cgi?req=doc\&base=CJI\&n=127387\#00010085127992935927 (дата обращения: 05.04.2021). 
10. Проект федерального закона «О внесении изменений в Федеральный закон «Об информации, информационных технологиях и о защите информации» [Электронный ресурc]. URL: https://regulation.gov.ru/ projects\#search=\%D0\%BE\%D0\%B1\%20\%D0\%B8\%D0\%BD\%D1\%84\%D0\%BE\%D1\%80\%D0\%BC\%D0\%B0\%D1\%86 \%D0\%B8\%D0\%B8\%20\%D0\%B8\%20\%D0\%B8\%D0\%BD\%D1\%84\%D0\%BE\%D1\%80\%D0\%BC\%D0\%B0\%D1\%86\%D0 \%B8\%D0\%BE\%D0\%BD\%D0\%BD\%D1\%8B\%D1\%85\%20\%D1\%82\%D0\%B5\%D1\%85\%D0\%BD\%D0\%BE\%D0\%BB\%D 0\%BE\%D0\%B3\%D0\%B8\%D1\%8F\%D1\%85\&npa=115660 (дата обращения: 05.04.2021).

11. Федеральный закон «О персональных данных» от 27.07.2006 № 152-Ф3 (последняя редакция). [Электронный ресурc]. URL: http://www.consultant.ru/document/cons_doc_LAW_61801/ (дата обращения: 05.04.2021).

12. Федеральный закон «О внесении изменений в части первую, вторую и статью 1124 части третьей Гражданского кодекса Российской Федерации» от 18.03.2019 N 34-Ф3 (последняя редакция). [Электронный ресурс]. URL: http://www.consultant.ru/document/cons_doc_LAW_320398/ (дата обращения: 05.04.2021). 